\title{
VIDEO PROMOSI WISATA “CIKAL ADVENTURE” DI KECAMATAN PADARINCANG
}

\author{
Desmira1), Didik Aribowo²), Ratna Ekawati3), Arum Wahyuni Purbohastuti4) \\ 1Fakultas Keguruan dan Ilmu Pendidikan, Universitas Sultan Ageng Tirtayasa \\ 4Fakultas Ekonomi dan Bisnis, Universitas Sultan Ageng Tirtayasa
}

Email: desmira@untirta.ac.id1,d_aribowo@untirta.ac.id2, ratnaekawati@untirta.ac.id3, arum_wp@untirta.ac.id 4

\begin{abstract}
Abstrak
Padarincang merupakan salah satu kecamatan di Provinsi Banten. Padarincang memiliki potensi unggulan pada beberapa bidang, khususnya sektor pariwisata. Cikal Adventure merupakan salah satu potensi wisata dengan keunggulan wisata alam dan petualangan. Wahana-wahana wisata Cikal Adventure meliputi river tubing, paintball, camping ground, dan outbond. Akses sarana transportasi menuju Cikal Adventure cukup mudah dijangkau, serta sarana dan prasarana di tempat wisata sangat memadai. Namun belum banyak wisatawan baik dari dalam dan luar Padarincang mengetahui obyek wisata Cikal Adventure. Tujuan kegiatan pengabdian masyarakat ini adalah mempromosikan ke khalayak luas tempat wisata Cikal Adventure melalui video yang diupload pada kanal digital Youtobe. Metode pengabdian meliputi observasi, wawancara, pengembangan video promosi wisata, dan umpan balik terhadap video promosi wisata. Respon pengunjung dan masyarakat terhadap video promosi wisata Cikal Adventure sangat baik dan masyarakat menjadi sangat tertarik untuk berkunjung ke Cikal Adventure. Hal tersebut ditunjukkan dengan hasil angket yang dibagikan pada responden: 1) $98 \%$ responden menyatakan tampilan video sangat menarik, 2) $86 \%$ menjelaskan isi video sangat mudah dipahami, 3) 95\% responden menyatakan sangat tertarik untuk berkungjung ke Cikal Adventure setelah menonton video.
\end{abstract}

Keywords: Video promosi wisata, Kecamatan Padarincang, Cikal Adventure

\begin{abstract}
Padarincang is one of the districts in Banten Province. Padarincang has excellent potential in several fields, especially the tourism sector. Cikal Adventure is one of the natural tourism potentials with the advantages of nature and adventure tourism. Cikal Adventure's attractions include river tubing, paintball, camping ground, and outbound. Access to transportation facilities to Cikal Adventure is quite easy to reach, and the facilities and infrastructure at the tourist attractions are very adequate. However, not many tourists from both inside and outside Padarincang know about Cikal Adventure tourism objects. The purpose of this community service activity is to promote to a wide audience the Cikal Adventure tourist spot through videos uploaded on the Youtobe digital channel. Service methods include observation, interviews, development of travel promotion videos, and feedback on travel promotional videos. The response of visitors and the public to the promotional video for the Cikal Adventure tour was very good and the community became very interested in visiting Cikal Adventure. This is indicated by the results of the questionnaire distributed to the respondents: 1) $98 \%$ of respondents stated that the appearance of the video was very interesting, 2) $86 \%$ explained that the contents of the video were very easy to understand, 3) $95 \%$ of respondents stated that they were very interested in visiting Cikal Adventure after watching the video.
\end{abstract}

Keywords: Video promosi wisata, Kecamatan Padarincang, Cikal Adventure 


\section{PENDAHULUAN}

“Kebijakan otonomi daerah merupakan kebijakan yang memberikan wewenang kepada daerah untuk mengurus dan mengatur kebutuhan masyarakat sesuai dengan karakteristik daerahnya. Oleh karena itu, konsep pembangunan harus lebih diarahkan lagi pada pembangunan berbasis tingkatan terendah dalam suatu struktur pemerintahan, yaitu desa" (Rahayuningsih et al., 2019).

“Kabupaten Serang merupakan salah satu dari delapan kabupaten/kota di Propinsi Banten, terletak diujung barat bagian utara pulau jawa dan merupakan pintu gerbang utama yang menghubungkan pulau Sumatera dengan pulau Jawa dengan jarak kurang lebih $70 \mathrm{KM}$ dari Jakarta, Ibukota negara Indonesia. Kondisi lahan di kabupaten Serang terbagi menjadi dua bagian yaitu kawasan lindung dan kawasan budidaya" (Hariyanto, 2020).

"Pengembangan sektor pariwisata merupakan salah satu instrumen yang sangat efektif dalam upaya mendorong pembangunan daerah, pemberdayaan masyarakat, serta dalam upaya peningkatan perekonomian masyarakat di suatu daerah di samping usaha menurunkan tingkat kemiskinan"(Wisata, Di, Bumi, \& Studi, 2019). “Dapat disebutkan demikian karena sektor pariwisata adalah sektor yang dapat dikembangkan oleh daerah-daerah. Pembangunan pariwisata pedesaaan diharapkan menjadi suatu model pembangunan pariwisata berkelanjutan sesuai dengan kebijakan pemerintah pada bidang pariwisata" (Wisata et al., 2019). Pembangunan berkelanjutan diformulasikan sebagai pembangunan yang berusaha memenuhi kebutuhan hari ini tanpa mengurangi kemampuan generasi yang akan datang dalam memenuhi kebutuhan mereka (Dan, Pariwisata, Kecamatan, \& Kabupaten, n.d.).

Padarincang merupakan kecamatan di Kabupaten Serang, Provinsi Banten. Kecamatan Padarincang terbagi menjadi empat belas desa antara lain: Barugbug, Batu Kawung, Bugel, Cibojong, Ciomas, Cipayung, Cisasat, Cisatuk, Curug Goong, Kadu Kempong, Kadubeureum, Kelumpang, Kramatlaban, dan Padarincang.

Kecamatan Padarincang memiliki bergaman potensi yang belum dikembangkan secara maksimal, misalnya potensi ekonomi dan pariwisata. Pusat perputaran perekonomian di Padarincang adalah pasar tradisional. Pasar tradisional di Padarincang beroperasi pada hari Senin dan Kamis selalu dipadati oleh pedagang dan pembeli baik dari dalam atau luar Padarincang.

Potensi lainnya kecamatan Padarincang adalah sektor pariwisata. Potensi wisata alam belum dikenal oleh wisatan secara luas karena kurangnya promosi baik pada media cetak ataupun digital. Sektor wisata di Padarincang apabila dikelola dan dipromosikan dengan profesional berpotensi untuk meningkat perekonomian masyarakat dan daerah. Beberapa tempat wisata di kecamatan Padarincang meliputi Wisata Air Terjun Curug Cigumawang, Wisata Tubing dan permainan alam "Cikal Adventure", 
Pemandian Air panas Batukuwung,

Pemandian Air Cirahab, Curug Cikotak dan Bukit Farm Waru Wangi.

Pembangunan merupakan kunci utama yang dapat meningkatkan taraf kehidupan masyarakat, salah satunya adalah peningkatan pembangunan sektor pariwisata yang telah memberikan kontribusi yang signifikan. Pembangunan sektor pariwisata pada intinya adalah sumber daya alam, , dengan demikian masyarakat juga memperoleh hasil dan ikut menikmati potensi-potensi yang ada di daerah sekitarnya. Masyarakat dapat dengan mudah memperoleh keuntungan baik dari segi ekonomi, sosial, maupun budaya (Hak \& Pendidikan, 2019).

Cikal Adventure merupakan tempat wisata unggulan di Padarincang menawarkan keindahan alam dan petualangan di kawasan lereng bukit. Sarana transportasi dan infrastruktur di tempat wisata "Cikal Adventure" cukup memadai akan tetapi kunjungan wisatawan belum maksimal baik pada weekday maupun weekend. Salah satu penyebabnya belum banyak wisatawan yang mengetahui tempat wisata tersebut dan promosi belum dilakukan secara maksimal.

Masa pandemi covid-19 berimbas pada semua aspek kehidupan masyarakat terutama sektor perekonomian, pendidikan, dan pariwasata. Perekonomian di kecamatan Padarincang mengalami penurunan akhibat pandemi dimana daya beli masyarakat berkurang karena sebagian besar pekerja bekerja dari rumah, dan terjadi pemutusan hubungan secara sepihak oleh beberapa perusahaan. Guna menghindari menurunnya perekonomian di Padarincang transaksi jual beli di pasar tetap berjalan seperti biasa akan tetapi tetap menaati protokol kesehatan. Pengunjung pasar diwajibkan untuk menggunakan masker dan menjaga jarak saat berbelanja.

Pandemi covid-19 berdampak langsung pada sektor parawisata. Tempat-tempat wisata diwajibkan ditutup selama beberapa bulan dan dibuka kembali pada era kebiasaan baru. Pembukaan tempat wisata pada era kebiasaan baru dengan menaati protokol kesehatan secara ketat dengan membatasi jumlah pengunjung, dan mewajibkan penggunaan masker. Pembukaan kembali tempat wisata "Cikal Adventure" selama era kebiasan baru belum banyak diketahui masyarakat secara luas. Tujuan kegiatan pengabdian masyarakat ini adalah membuat video promosi wisata "Cikal Adventure" pada era kebiasan baru.

seperti halnya cikal adventure di Kecamatan Padarincang Kabupaten Serang Propinsi Banten ini . Semoga dengan adanya pandemic covid 19 ini tentunya harapan usaha jasa pariwisata di Kecamatan Padarincang tetap terus berkembang demi menunjang sektor perkonomian masyarakat dalam skala mikro, kecil dan menengah.

\section{METODE PENGABDIAN}

Tahapan-tahapan pengembangan video promosi "Cikal Adventure" meliputi:

a. Observasi

Obervasi merupakan salah satu metode penelitaian mengamati bagaimana obyek atau 
kejadian yang sedang berlangsung ("A Method for Observing and Evaluating Writing Lab Tutorials on JSTOR," n.d.; Papini, Datan, \& McCluskey-Fawcett, 1988). Observasi tahapan penelitian ini dilakukan dengan melihat langsung ke lapangan tempat lokasi wisata yang ada di Padarincang terutama di tempat air terjun yang dijadikan objek penelitian dalam pembuatan video. Sebelum observasi ke tempat wisata dilakukan silahturahmi dengan perangkat desa Padarincang.

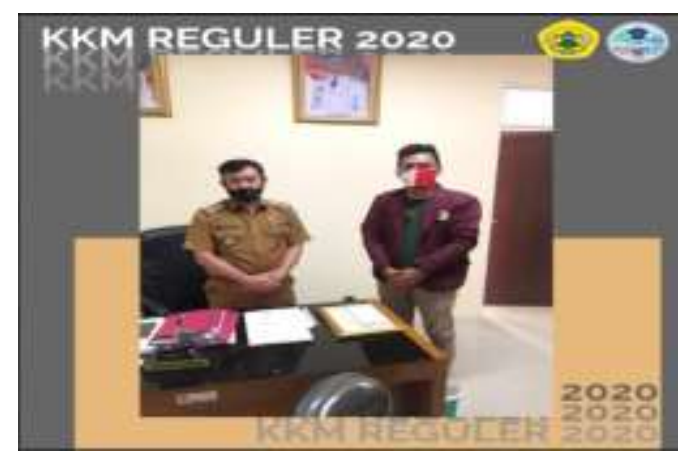

Gambar 1. Silahturahmi dengan perangkat desa

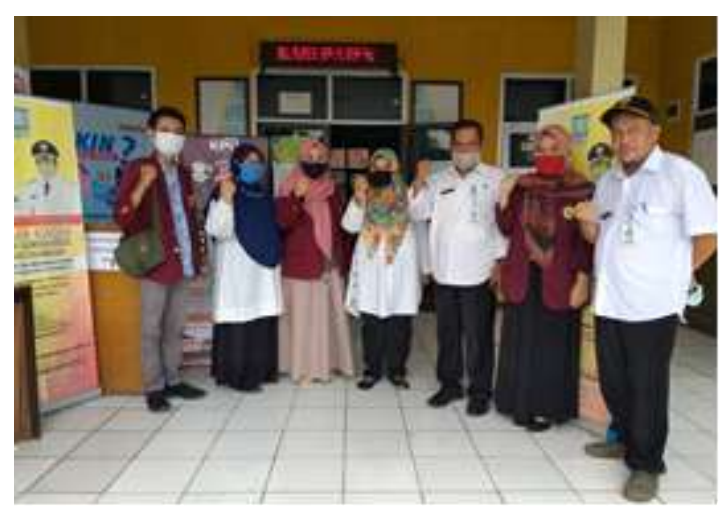

Gambar 2. Silahturami dengan perangkat desa

b. Wawancara

Wawancara bertujuan menggali informasi individu secara mendalam (Cohen, Manison, \& Morrison, 2018). Wawancara semi terstruktur kepada pengelola dan instruktur di "Cikal Adventure".

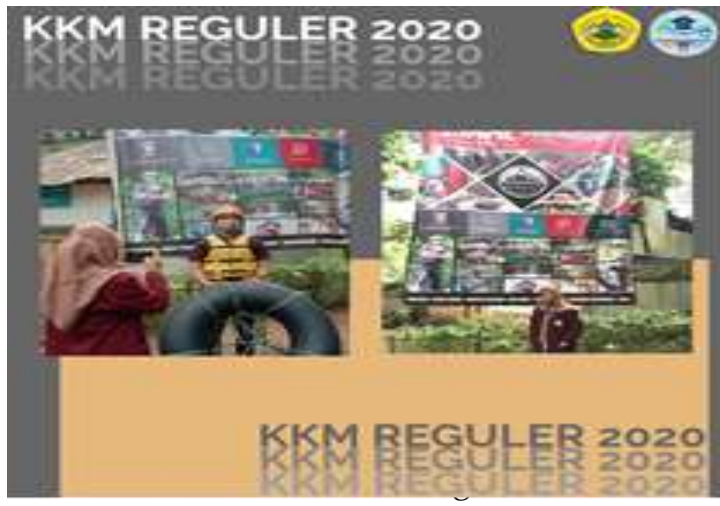

\section{lokasi wisata}

c. Pembuatan video promisi wisata

Padarincang "Cikal Adventure". Acuan pemubuatan video promosi wisata adalah hasil analisis kegiatan observasi langsung ke tempat wisata dan wawancara pemangku kebijakan tempat wisata Padarincang.

\section{HASIL DAN PEMBAHASAN}

Tahapan pengembangan video promosi wisata "Cikal Adventure" meliputi observasi, wawancara, dan desain pengembangan video. Tahap observasi awal dilakukan sebanyak dua kali dengan cara pengamtan secara langsung di tempat wisata. Tujuan obervasi adalah memetakan keindahan wilayah dan jenis wisata unggulan "Cikal Adventure" yang akan ditampilkan pada video.

Hasil deskripsi obervasi "Cikal Adventure": 1) wisata "Cikal Adventure" terletak pada lereng gunung dengan pepohonan hijau yang sejuk, 2) sepanjang lereng gunung terdapat sungai Cikalumpang dengan batu-batu besar membentuk jeramjeram sepanjang sungai, 3) arena wisata di "Cikal Adventure" meliputi river tubing menggunakan ban sepanjang sungai 
Cikalumpang, paintball, dan wahana outbond,

4) Fasilitas family gathering tersedia tempat camping, aula, dan homestay.

Hasil analisis pada tahap wawancara sebagai landasan pengembangan desain video promosi wisata. Contoh deskripsi hasil wawancara dengan pengelola "Cikal Adventure" meliputi: 1) keunikan river tubing adalah menggunakan ban pada setiap pengunjung selama menyusuri sungai, 2) paket-paket trip pada river-tubing ada long-trip dan short-trip, 3) setiap peserta river tubing diwajibkan menggunakan pelampung dan helm sebagai upaya menjaga keselamatan pengunjung, 4) tersedia paket dalam kelompok kecil dan besar untuk wahana permainan paintball dengan bantuan instruktur ahli, 5) tersedia paket khusus camping ground dengan fasilitas penyewaan tenda, 6) selama masa kebiasaan baru para pengunjung diwajibkan menaati protokol kesehatan teruma penggunaan masker.

Desain video promosi wisata "Cikal Adventure" dikembangkan berdasarkan hasil analisis pada tahap observasi dan wawancara. Desain frame per frame pada video promosi wisata yaitu: 1) judul video, 2) profil Cikal Adventure, 3) wahana wisata yang tersedia di Cikal Adventure, 4) sarana dan prasarana penunjang di tempat wisata, 5) Protokol kesehatan yang harus ditaati pengunjung selama era kebisaan baru. Video promosi wisata Cikal Adventure diupload ke kanal digital seperti Youtube supaya lebih mudah diakses oleh banyak masyarakat luas baik yang dari dalam maupun luar Padarincang.

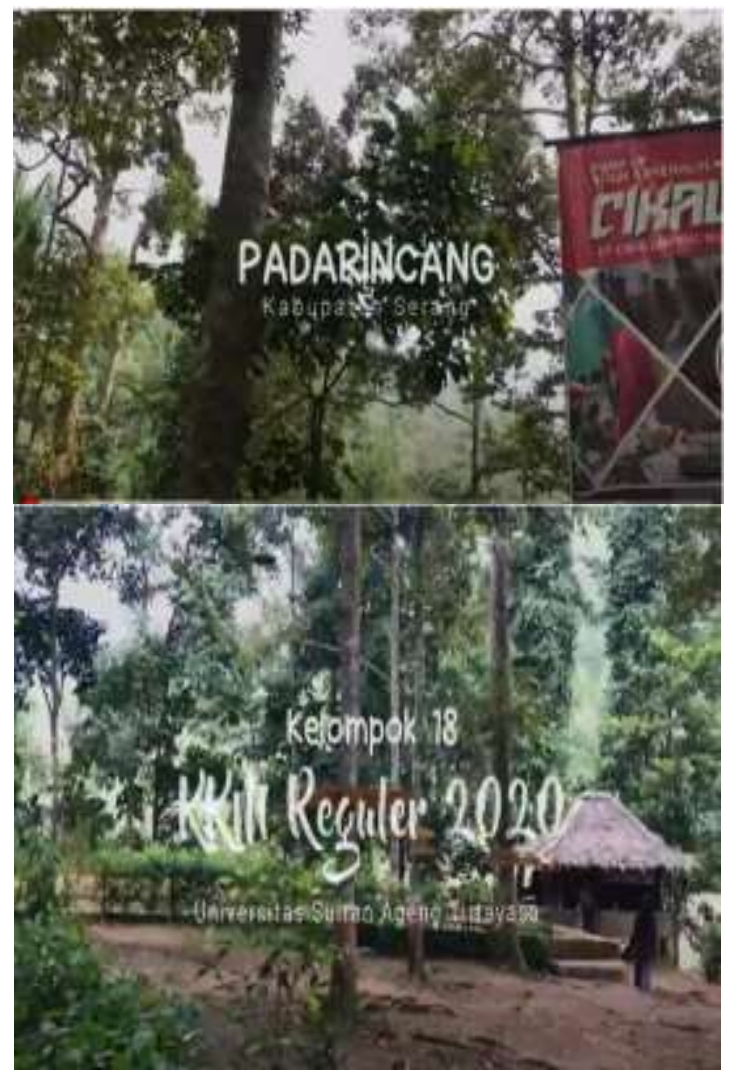

Gambar 4. Contoh frame video promosi Cikal

\section{Adventure}

Tahap akhir untuk mengetahui sejauhmana manfaat video promosi, maka diserbarluaskan berupa isian angket pada pengunjung dan masyarakat luas. Poin-poin utama pertanyaan di isian angket tersebut antara lain: 1) kemenarikan tampilan video, 2) kemudahan isi video dipahami masyarakat luas, 3) kertertarikan masyarakat untuk mengunjungi tempat wisata Cikal Adventure.

\section{KESIMPULAN}

Tahapan-tahapan pengembangan video promosi Cikal Adventure berlangsung dengan baik. Adapun respon dari pengunjung dan masyarakat tentang kebermanfaat video 
promosi Cikal Adventure sangat baik. Hal tersebut ditunjukkan sebagai berikut,

1) $98 \%$ responden menyatakan tampilan video sangat menarik,

2) $86 \%$ menjelaskan isi video sangat mudah dipahami,

3) $95 \%$ responden menyatakan sangat tertarik untuk berkungjung ke Cikal Adventure setelah menonton video.

\section{UCAPAN TERIMAKASIH}

Dengan terlaksana kegiatan pengabdian di Kecamatan Padarincang saya sebagai penulis sangat berterima kasih yang telah menerima peserta KKM, Universitas Sultan Ageng Tirtayasa Tahun 2020 Kelompok 18 yang berasal dari daerah Kecamatan Padarincang dan Kecamatan Pabuaran. Dr.Rusmana,Ir.,MP yang telah memberikan kesempatan penulis untuk membimbing mahasiswa KKM Reguler Universitas Sultan Ageng Tirtayasa Tahun 2020. Serta semua pihak mahasiswa KKM kelompok 18 Universitas Sultan Ageng Tirtayasa Tahun 2020 yang telah terlibat langsung dalam pelaksanna KKM regular .

\section{DAFTAR PUSTAKA}

A Method for Observing and Evaluating Writing Lab Tutorials on JSTOR. (n.d.).

Cohen, L., Manison, L., \& Morrison, K. (2018). Research Methods in Education (Eighth Edi). Oxon: Routledge Falmer, Taylor and Francis Group.

Dan, P., Pariwisata, P., Kecamatan, S., \& Kabupaten, C. (n.d.). Inovasi Kebijakan Partisipasi Publik dalam Pengelolaan dan

Sururi ), 110-121.

Hak, P., \& Pendidikan, H. A. K. (2019). No Title, 3(1), 100-115. Hariyanto, B. (2020). Pengembangan masyarakat berwirausaha desa pasauran kecamatan cinangka kabupaten serang banten, 2(1), 48-55.

Papini, D. R., Datan, N., \& McCluskey-Fawcett, K. A. (1988). An observational study of affective and assertive family interactions during adolescence. Journal of Youth and Adolescence, 2(1), 477-492.

Rahayuningsih, Y., Budiarto, S., Isminingsih, S., Banten, B. P., Sultran, U., Tirtayasa, A., ... Sukaratu, D. (2019). PERAN BUMDES DALAM PENGUATAN EKONOMI DESA SUKARATU KABUPATEN SERANG, BANTEN THE ROLE OF VILLAGE OWNED ENTERPRISE IN STRENGHTENING THE ECONOMIC OF SUKARATU VILLAGE , SERANG REGENCY , BANTEN PROVINCE, (2).

Wisata, D., Di, E., Bumi, D., \& Studi, J. (2019). Universitas Bina Bangsa, $3(1)$. 